\title{
The long non-coding RNA H19 - a new player in hepatocellular carcinoma
}

\author{
Maximilian A. Ardelt ${ }^{1}$ and Johanna Pachmayr ${ }^{2, *}$ \\ ${ }^{1}$ Department of Pharmacy, Pharmaceutical Biology, University of Munich, Munich, Germany. \\ ${ }^{2}$ Pharmacy, Pharmaceutical Biology\&Clinical Pharmacy, Paracelsus Medical University, Salzburg, Austria. \\ * Corresponding Authors: \\ Johanna Pachmayr, Pharmacy, Pharmaceutical Biology\&Clinical Pharmacy, Paracelsus Medical University, Salzburg, Austria; E-mail: \\ johanna.pachmayr@pmu.ac.at
}

Hepatocellular carcinoma (HCC) is among the most prevalent and lethal cancers worldwide [1]. Incidence is increasing and due to its high chemoresistance, the therapeutic options are limited and HCC has risen to become one of the leading causes of cancer-related death [2]. Thus, a detailed characterization of the mechanisms of HCC chemoresistance is urgently required in order to find new therapeutic approaches to overcome HCC chemoresistance.

The study by Schultheiss et al. suggests an interesting player to overcome chemoresistance in HCC: the long noncoding RNA (IncRNA) H19 [3]. LncRNAs have recently emerged as pivotal players in cancer, due to their contribution to cancer development, metastasis and chemoresistance [4]. H19 was associated with various types of cancer, but its role in cancer is conflicting, as tumorpromoting and tumor-suppressive actions have been demonstrated [5-7]. H19 was shown to be regulated under inflammatory conditions [5] and has been linked with HCC that represents a type of tumor that is associated with inflammatory conditions such as found in viral hepatitis as well as in alcoholic and non-alcoholic steatohepatitis [8-10]. However, the reports about $\mathrm{H} 19$ in $\mathrm{HCC}$ are contradictory and $\mathrm{H} 19$ was described both to promote as well as to suppress tumor development [9-11]. Thus, the role of H19 in $\mathrm{HCC}$ is still unclear.

In order to investigate the expression of H19 in HCC, Schultheiss et al. used four independent patient cohorts which revealed a decreased expression of $\mathrm{H} 19$ in human HCC tissue compared to non-tumorous tissue. However, interestingly, although $\mathrm{H} 19$ was downregulated in HCC, in each of the investigated patient cohorts a high $\mathrm{H} 19$ expres- sion was observed in a small patient subgroup. This might explain the contradictory findings about $\mathrm{H} 19$ expression in small patient cohorts. In line with $\mathrm{H} 19$ levels, the expression of miR 675 , which is encoded by $H 19[12,13]$, was decreased, whereas the expression of the mRNA binding protein EVAL1, a negative regulator of miR-675, was increased in HCC tissues.

Subsequently, the authors addressed the mechanisms underlying the decreased expression of $\mathrm{H} 19$ in HCC. H19 expression can be regulated by loss of imprinting (LOI) and by differential promoter methylation [14]. Schultheiss et al. showed that the decreased $\mathrm{H} 19$ expression was not due to LOI. Interestingly, H19 promoter methylation was decreased in HCC compared to normal liver tissue, suggesting that decreased expression of $\mathrm{H} 19$ correlates with decreased promotor methylation. However, elevated gene expression is normally based on decreased promoter methylation. Nevertheless, an association of hypermethylation and increased gene expression has been described as well [15]. Thus, the relationship between H19 promotor methylation and expression in HCC needs further investigation and will be an interesting topic for further research.

To further determine the function and regulation of $\mathrm{H} 19$ in HCC, the authors used three different HCC cell lines, including HepG2, Plc/Prf/5, and Huh7. H19 overexpression impaired clonogenic growth and improved the response of $\mathrm{HCC}$ cells to the treatment with sorafenib and doxorubicin, suggesting a chemosensitizing effect of H19. However, determination of the influence of $\mathrm{H} 19$ overexpression and knockdown on cell viability and proliferation revealed cell line specific differences: except for an elevation of viability

Comment on this issue's Christina S. Schultheiss, Stephan Laggai, Beate Czepukojc, Usama K. Hussein, Markus List, Ahmad Barghash, Sascha Tierling, Kevan Hosseini, Nicole Golob-Schwarzl, Juliane Pokorny, Nina Hachenthal, Marcel Schulz, Volkhard Helms, Jörn Walter, Vincent Zimmer, Frank Lammert, Rainer M. Bohle, Luisa Dandolo, Johannes Haybaeck, Alexandra K. Kiemer, Sonja M. Kessler (2017). The long non-coding RNA H19 suppresses carcinogenesis and chemoresistcance in hepatocellular carcinoma. Cell Stress 1(1): 37-54. doi: 10.15698/cst2017.10.105 
of HepG2 cells, HCC cell viability was not affected by H19 overexpression or knockdown. Moreover, whereas proliferation of HepG2 cells was not affected, H19 overexpression reduced proliferation of Plc/Prf/5 and Huh7 cells. These data suggest a rather context-dependent function of $\mathrm{H} 19$ in HCC. Investigating $\mathrm{H} 19$ signaling suggested that neither miR-675 nor ELAV1 or IGF2 contributed to the sensitizing effect of $\mathrm{H} 19$, as these components were not modulated in cells with $\mathrm{H} 19$ upregulation. Thus, the signaling network of $\mathrm{H} 19$ in $\mathrm{HCC}$ remains an interesting question for future research.

In order to evaluate whether $\mathrm{H} 19$ contributes to chemoresistance, Schultheiss et al. generated doxorubicinand sorafenib-resistant HepG2, Plc/Prf/5 and Huh7 cells. In fact, downregulation of $\mathrm{H} 19$ in the resistant cell lines suggested an association of $\mathrm{H} 19$ suppression with chemoresistance. Moreover, $\mathrm{H} 19$ promotor methylation was changed during chemoresistance, but again cell-line specific differences were observed: all three sorafenib-resistant cell lines as well as doxorubicin-resistant HUH7 cells showed elevated promoter methylation with differences in the specific CpG sites, whereas doxorubicin-resistant HepG2 and PIc/Prf/5 cells showed a heterogenous hyperor hypomethylation of the different $\mathrm{CpG}$ sites. As most of the changes were observed nearest to the transcription start site, the authors suggested that the modified promotor methylation contributes to decreased $\mathrm{H} 19$ expression during chemoresistance. Therefore, Schultheiss et al. investigated the influence of the DNA-demethylating agent 5-azacytidine on HCC cell chemoresistance. 5-azacytidine decreased $\mathrm{H} 19$ promoter methylation and increased $\mathrm{H} 19$ expression in HepG2 and Huh7 cells but not in Plc/Prf/5 cells. Moreover, 5-azacytidine sensitized HCC cells to doxorubicin treatment. As $\mathrm{H} 19$ overexpression improved cell death induction by doxorubicin and inhibited proliferation

\section{REFERENCES}

1. Jemal A, Bray F, Center MM, Ferlay J, Ward E, Forman D (2011). Global cancer statistics. CA Cancer J Clin 61(2): 69-90. doi: 10.3322/caac.20107

2. Bruix J, Sherman M, American Association for the Study of Liver D (2011). Management of hepatocellular carcinoma: an update. Hepatology 53(3): 1020-1022. doi: 10.1002/hep.24199

3. Christina S. Schultheiss, Stephan Laggai, Beate Czepukojc, Usama K. Hussein, Markus List, Ahmad Barghash, Sascha Tierling, Kevan Hosseini, Nicole Golob-Schwarzl, Juliane Pokorny, Nina Hachenthal, Marcel Schulz, Volkhard Helms, Jörn Walter, Vincent Zimmer, Frank Lammert, Rainer M. Bohle, Luisa Dandolo, Johannes Haybaeck, Alexandra K. Kiemer, Sonja M. Kessler (2017). The long non-coding RNA H19 suppresses carcinogenesis and chemoresistcance in hepatocellular carcinoma. Cell Stress 1(1): 37-54. doi: 10.15698/cst2017.10.105

4. Esteller M (2011). Non-coding RNAs in human disease. Nat Rev Genet 12(12): 861-874. doi: 10.1038/nrg3074

5. Wang WT, Ye H, Wei PP, Han BW, He B, Chen ZH, Chen YQ (2016). LncRNAs $\mathrm{H} 19$ and HULC, activated by oxidative stress, promote cell migration and invasion in cholangiocarcinoma of chemoresistant HCC cells, H19 overexpression was suggested as potential approach to overcome chemoresistance in HCC.

Finally, the influence of $\mathrm{H} 19$ on tumor induction was investigated. In fact, $\mathrm{H} 19$ deficient mice demonstrated increased tumor development by the carcinogen diethylnitrosamine (DEN) with tumors that showed increased cell proliferation as well as dysplastic lesions characteristic for liver carcinogenesis.

In summary, the study by Schultheiss et al. shows that the IncRNA H19 is downregulated in HCC tissues and that it suppresses chemoresistance and tumorigenesis. The contribution of $\mathrm{H} 19$ promotor methylation and the cell-line specific effects of H19 open exciting questions for future research. To conclude, the study by Schultheiss et al. helps to understand the function of $\mathrm{H} 19$ in $\mathrm{HCC}$ and suggests $\mathrm{H} 19$ as a potential target to overcome chemoresistance in HCC.

\section{CONFLICT OF INTEREST}

None.

\section{COPYRIGHT}

(C) 2017 Ardelt and Pachmayr. This is an open-access article released under the terms of the Creative Commons Attribution (CC BY) license, which allows the unrestricted use, distribution, and reproduction in any medium, provided the original author and source are acknowledged.

Please cite this article as: Maximilian A. Ardelt and Johanna Pachmayr (2017). The long non-coding RNA H19 - a new player in hepatocellular carcinoma. Cell Stress 1(1): 4-6. doi: 10.15698/cst2017.10.102

through a ceRNA manner. Journal of hematology \& oncology 9(1): 117. doi: 10.1186/s13045-016-0348-0

6. Ohtsuka $M$, Ling $H$, Ivan $C$, Pichler $M$, Matsushita D, Goblirsch $M$, Stiegelbauer $V$, Shigeyasu $K$, Zhang $X$, Chen $M$, Vidhu F, Bartholomeusz GA, Toiyama Y, Kusunoki M, Doki Y, Mori M, Song S, Gunther JR, Krishnan S, Slaby O, Goel A, Ajani JA, Radovich M, Calin GA (2016). H19 Noncoding RNA, an Independent Prognostic Factor, Regulates Essential Rb-E2F and CDK8-beta-Catenin Signaling in Colorectal Cancer. EBioMedicine 13:113-124. doi: 10.1016/j.ebiom.2016.10.026

7. Wang SH, Wu XC, Zhang MD, Weng MZ, Zhou D, Quan ZW (2016). Long noncoding RNA H19 contributes to gallbladder cancer cell proliferation by modulated miR-194-5p targeting AKT2. Tumour Biol 37(7): 9721-9730. doi: 10.1007/s13277-016-4852-1

8. El-Serag HB, Rudolph KL (2007). Hepatocellular carcinoma: epidemiology and molecular carcinogenesis. Gastroenterology 132(7): 2557-2576. doi: 10.1053/j.gastro.2007.04.061

9. Yoshimizu T, Miroglio A, Ripoche MA, Gabory A, Vernucci M, Riccio A, Colnot S, Godard C, Terris B, Jammes H, Dandolo L (2008). The $\mathrm{H} 19$ locus acts in vivo as a tumor suppressor. Proc 
Natl Acad Sci U S A 105(34): 12417-12422. doi: 10.1073/pnas.0801540105

10. Matouk IJ, DeGroot N, Mezan S, Ayesh S, Abu-lail R, Hochberg A, Galun E (2007). The H19 non-coding RNA is essential for human tumor growth. PLoS One 2(9): e845. doi: 10.1371/journal.pone.0000845

11. He Y, Meng XM, Huang C, Wu BM, Zhang L, Lv XW, Li J (2014). Long noncoding RNAs: Novel insights into hepatocelluar carcinoma. Cancer Lett 344(1): 20-27. doi: 10.1016/j.canlet.2013.10.021

12. Cai $X$, Cullen BR (2007). The imprinted $H 19$ noncoding RNA is a primary microRNA precursor. Rna 13(3): 313-316. doi: 10.1261/rna.351707
13. Keniry A, Oxley D, Monnier P, Kyba M, Dandolo L, Smits G, Reik W (2012). The $\mathrm{H} 19$ lincRNA is a developmental reservoir of miR-675 that suppresses growth and Igf1r. Nat Cell Biol 14(7): 659-665. doi: 10.1038/ncb2521

14. Gabory A, Ripoche MA, Yoshimizu T, Dandolo L (2006). The $\mathrm{H} 19$ gene: regulation and function of a non-coding RNA. Cytogenetic and genome research 113(1-4): 188-193. doi: $10.1159 / 000090831$

15. Wu J, Qin Y, Li B, He WZ, Sun ZL (2008). Hypomethylated and hypermethylated profiles of H19DMR are associated with the aberrant imprinting of IGF2 and $\mathrm{H} 19$ in human hepatocellular carcinoma. Genomics 91(5):

443-450. doi: 